\title{
Comportamento de Leitões na Fase de Creche Criados em Região de Clima Tropical
}

\author{
Nursery Piglets Behavior Created in Tropical Climate Region
}

\author{
Rebeca de Andrade Parente; ${ }^{\mathrm{a}}$ Belise Maria Oliveira Bezerra ${ }^{\mathrm{a}}$; Tiago Silva Andrade ${ }^{\mathrm{a}}$, Lina Raquel Santos Araújo \\ Ricardo Toniolli*b
}

\begin{abstract}
aUniversidade Estadual do Ceará, Programa de Pós-Graduação Stricto Sensu em Ciências Veterinárias. CE, Brasil.
${ }^{\mathrm{b}}$ Universidade Estadual do Ceará. Laboratório de Reprodução Suína e Tecnologia de Sêmen. CE, Brasil.

*E-mail: ricardo.toniolli@uece.br
\end{abstract}

\begin{abstract}
Resumo
O ambiente em que o animal habita está relacionado com o comportamento que esse vai expressar, portanto, problemas comportamentais podem ser indicativos de deficiências ambientais ou de manejo, alterando o bem-estar do animal. O objetivo deste trabalho foi avaliar o comportamento de leitões, na fase de creche, de acordo com variações de temperatura e umidade do ambiente em granja comercial localizada em Maranguape-Ceará. Foram utilizados 60 leitões de ambos os sexos desmamados aos 21 dias de idade com peso médio de 6,1 $\pm 0,4 \mathrm{~kg}$ distribuídos em quatro baias de 15 animais cada, que foram observados em dois horários por dia. Foi instalada uma câmera, na parte superior da baia, para fazer a filmagem dos leitões, que filmava das 05:00 horas às 07:00 horas da manhã, e de 12:00 horas às 14:00 horas da tarde, além de serem registradas a temperatura e umidade, através de um termohigrômetro. Para analisar o comportamento dos animais foi utilizada uma ficha de etograma, calculando-se os percentuais de ocorrência de cada comportamento. As médias de temperatura registradas foram 25 e $28{ }^{\circ} \mathrm{C}$ e de umidade $84 \%$ e $73 \%$ para os horários 05:00 horas e 12:00 horas, respectivamente. Os animais passaram a maior parte do tempo dormindo ou deitados (69 e 70\%) em ambos os horários de observação. O comportamento apresentado pelo animal pode ser um indicativo de conforto térmico, situação essencial para expressão de seu potencial produtivo.
\end{abstract}

Palavras-chave: Bem-Estar Animal. Conforto Térmico. Etograma. Suinocultura.

\begin{abstract}
The environment in which the animal lives is related to the behavior it will express, so behavioral problems may be indicative of environmental or management deficiencies, altering the animal's welfare. The objective of this work is to evaluate the piglets behavior in the nursery phase according to temperature and humidity variations in a commercial farm located in Maranguape-Ceará. Sixty piglets of both sexes weaned at 21 days of age with an average weight of $6.1 \pm 0.4 \mathrm{~kg}$ were used, distributed in four pens of 15 animals each, which were observed at two times per day. A camera was installed in the upper part of the pen for filming the piglets, which filmed from 5:00 am to 7:00 am, and from 12:00 pm to 2:00 pm, and was recorded at temperature and humidity through a hygrometer term. To analyze the animals behavior, an ethogram form was used. The average temperatures recorded were 25 and $28^{\circ} \mathrm{C}$ and humidity $84 \%$ and 73\% at 05:00 a.m. and 12:00 p.m. hours, respectively. The animals spent most of the time sleeping or lying down (69 and 70\%) at both observation times. The behavior shown by the animal can be an indication of thermal comfort, an essential situation for the expression of its productive potential.
\end{abstract}

Keywords: Animal Welfare. Thermal Comfort. Ethogram. Pig Breeding.

\section{Introdução}

O sistema de produção de confinamento intensivo é o mais adotado no Brasil, por muitas vezes, os animais ficam expostos em condições de estresse. A China, os Estados Unidos e a União Europeia são grandes produtores e principais mercados consumidores de carne suína, e aprovaram diversas leis rigorosas relacionadas à produção de suínos e, para que o Brasil consiga exportar para esses países, os produtores deverão investir em algumas práticas que melhorem o bemestar dos animais (ABPA, 2016).

Fatores ambientais influenciam, diretamente e indiretamente, sobre a criação de suínos, levando à diminuição da produtividade, com consequentes danos à exploração (DAMASCENO et al., 2019). O comportamento animal está intimamente interligado ao ambiente no qual os animais são criados, sendo fundamental nas adaptações das funções biológicas e representa a parte do organismo que interage com o meio (SNOWDON, 1999).

Dentro do sistema de produção de suínos, a fase de creche (21 a 63 dias de vida) é fundamental, pois a capacidade de desenvolvimento subsequente na terminação já estará praticamente predeterminada ao final dessa fase. Diversos são os fatores relacionados com este desenvolvimento: genéticos (ganho de peso diário, conversão alimentar), sanitários, nutricionais, ambientais (umidade, temperatura, clima, instalações) e humanos (motivação dos funcionários, treinamento e adequadas práticas de manejo). Em função deste complexo de fatores inter-relacionados faz-se necessária uma visão macro do sistema, mas ao mesmo tempo focada em cada detalhe dessa fase de produção. Proporcionar um ambiente de 
qualidade, com controle sanitário adequado e confortável, é fundamental para um adequado desenvolvimento dos leitões na fase de creche (KUMMER et al., 2009).

Os problemas comportamentais podem ser sugestivos de deficiências ambientais e de manejo e, portanto, indicativos de alterações no bem-estar (ANDRADE et al., 2019). É possível verificar que suínos sob condições de estresse térmico (QUINIOU et al., 1999; KIEFER et al., 2009), mistura de lotes ou superlotação de baias (SPOOLDER et al., 1999) ou quando alojados em ambientes áridos, monótonos e com falta de substratos (CAMPOS et al., 2010) apresentam modificações no comportamento natural. É necessário o conhecimento do comportamento dos animais para que os sistemas de criação animal sejam aprimorados, resultando em melhoria do bemestar e do benefício econômico aos produtores (FOPPA et al., 2018).

O objetivo deste trabalho foi avaliar diariamente em diferentes horários, o comportamento de leitões na fase de creche de acordo com variações de temperatura e umidade do ambiente em granja comercial localizada no município de Maranguape-Ceará.

\section{Material e Métodos}

\subsection{Instalação e animais}

O experimento foi conduzido em granja comercial, localizada no município de Maranguape, CE. O galpão era de alvenaria, com telhas de barro, e dividido em 16 baias, sendo 8 em cada lado, nas quais foram alojados os animais. As baias eram suspensas, com piso de plástico removível e possuíam cortinas móveis nas laterais. Cada baia tinha $36 \mathrm{~m}^{2}(4,80 \mathrm{~m} \mathrm{x}$ 7,50 m) alojando um total de 60 leitões em cada uma. Todas as baias possuíam bebedouros tipo "nipple" e o comedouro tipo funil com cocho de plástico, garantindo o fornecimento de ração à vontade. Para realização do experimento, a fim de facilitar a visualização dos animais, a baia foi subdividida em 4, alojando 15 animais em cada quadrante. O protocolo experimental foi aprovado pela Comitê de Ética na utilização de animais da Universidade Estadual do Ceará (CEUA/ UECE), sob o número 6364557/2015.

Na lateral do galpão havia cortinas, quando a temperatura estava alta as cortinas ficavam abaixadas para que houvesse uma maior circulação do ar, e nos horários em que a temperatura era mais amena as cortinas eram levantadas, a fim de não ficar frio para os animais e nem haver uma oscilação de temperatura muito grande.

Foram utilizados 60 leitões desmamados de ambos os sexos, com idade média de 21 dias e peso médio de $6,1 \pm 0,4 \mathrm{Kg}$. Os animais saíram da creche aos 60 dias, com peso médio de $24,6 \mathrm{Kg}$.

\subsection{Delineamento experimental}

O experimento foi realizado no período de 06/02/2018 até 22/02/2018, com uma duração de 17 dias, com os animais já mais adaptados ao ambiente e iniciando após 19 dias de alojamento, ou seja, o experimento compreendeu a observação de leitões dos 40 aos 57 dias de idade.

Diariamente era colocada uma câmera (GoPro, modelo hero 3 plus silver edition, GoPro Inc., Califórnia, EUA), com lente angular, full HD 1080p, na parte superior da baia para fazer a filmagem dos leitões durante o experimento. A câmera filmava das 05:00 até às 07:00 horas da manhã, e de 12:00 horas às 14:00 horas da tarde. Foi feito avaliação das filmagens de todos os dias utilizando o etograma. Todos os dias pela manhã e tarde eram registradas a temperatura e umidade, através de um termo higrômetro digital (MT-240, Minipa, São Paulo, Brasil).

Para analisar o comportamento dos animais foi utilizada uma ficha de etograma (Quadro 1), semelhante a utilizada por Campos et al. (2010). Os resultados da observação das imagens foram digitalizados em uma ficha de etograma eletrônica. Para as análises das filmagens, a cada 10 minutos, o filme era pausado e contados quantos animais mordendo, brigando ou arranhando, fuçando a baia, fuçando o outro, dormindo ou deitado, comendo ou bebendo, locomovendo-se, parado ou excretando e brincando entre si. Sendo descartados os 10 primeiros e 10 últimos minutos da filmagem, para que a entrada e saída do galpão para instalação e desinstalação da câmera não interferisse no comportamento dos animais. Depois de contabilizado, calculou-se a porcentagem de cada comportamento. O objetivo deste trabalho foi avaliar o comportamento de leitões na fase de creche de acordo com variações de temperatura e umidade do ambiente em granja comercial localizada em Maranguape-Ceará.

Quadro 1 - Padrões de comportamento avaliados em etograma aplicado no experimento

\begin{tabular}{|l|l|}
\hline Comportamento & \multicolumn{1}{|c|}{ Descrição } \\
\hline $\begin{array}{l}\text { Comportamento } \\
\text { mordendo, } \\
\text { brigando ou } \\
\text { arranhando }\end{array}$ & $\begin{array}{l}\text { Animal brigando, mordendo ou arranhando } \\
\text { outros animais com os dentes. }\end{array}$ \\
\hline Fuçando a baia & $\begin{array}{l}\text { Animal fuçando o piso da baia, as laterais } \\
\text { ou ao redor do comedouro com o focinho. }\end{array}$ \\
\hline Fuçando o outro & $\begin{array}{l}\text { Animal fuçando a orelha, a cauda ou a } \\
\text { barriga do outro com o focinho. }\end{array}$ \\
\hline $\begin{array}{l}\text { Dormindo ou } \\
\text { deitado }\end{array}$ & $\begin{array}{l}\text { Animal deitado com o corpo em contato } \\
\text { com o piso ou estirado sobre esse, com } \\
\text { olhos fechados ou abertos. }\end{array}$ \\
\hline $\begin{array}{l}\text { Ingerindo } \\
\text { alimento ou água }\end{array}$ & $\begin{array}{l}\text { Animal ingerindo alimento (ração ou água) } \\
\text { no comedouro ou no bebedouro. }\end{array}$ \\
\hline Locomovendo-se & $\begin{array}{l}\text { Animal em movimento de caminhada pela } \\
\text { baia. }\end{array}$ \\
\hline $\begin{array}{l}\text { Parado ou } \\
\text { excretando }\end{array}$ & $\begin{array}{l}\text { Animal sentado (apoiado com a parte } \\
\text { posterior e as patas dianteiras no piso); } \\
\text { animal parado sobre o piso, apoiado nas } \\
\text { quatro patas e sem nenhum movimento } \\
\text { aparente ou animal excretando dejetos } \\
\text { (fezes e urina). }\end{array}$ \\
\hline $\begin{array}{l}\text { Brincando entre } \\
\text { eles }\end{array}$ & $\begin{array}{l}\text { Animal correndo dentro da baia ou animal } \\
\text { apoiado sobre o outro. }\end{array}$ \\
\hline
\end{tabular}




\subsection{Análise Estatística}

Os animais foram distribuídos em um delineamento inteiramente casualizado, cuja frequência média de comportamentos apresentados nos turnos manhã e tarde foram comparadas pelo teste de ManWhitney 5\%, por meio do Programa Estatístico R (The R Foundation for Statistical Computing, versão 3.5.2, 2018).

\section{Resultados e Discussão}

Os comportamentos dos animais não diferiram entre os horários de avaliação $(\mathrm{p}>0,05)$ e estão representados no Quadro 2. O comportamento dormindo ou deitado foi o mais frequente em ambos os períodos de observação, seguido do comportamento comendo ou bebendo. A temperatura média observada foi de $25^{\circ} \mathrm{C}$ às 05:00 horas e $28{ }^{\circ} \mathrm{C}$ às 12:00 horas, enquanto a umidade relativa do ar média foi de $84 \%$ e $73 \%$ para os mesmos horários (Quadro 3). Sendo a temperatura mais alta registrada de $30,7^{\circ} \mathrm{C}$ às $12: 00$ horas, e a mais baixa de 23, $6^{\circ} \mathrm{C}$ às 05:00 horas. Esses dados mostram que os animais não foram expostos ao estresse pelo calor na maior parte do período experimental, sendo a temperatura limítrofe para desencadear estresse pelo calor em leitões, nesta faixa etária, segundo Kummer et al. (2009), temperaturas superiores a 28 ${ }^{\circ} \mathrm{C}$ e inferiores a $22{ }^{\circ} \mathrm{C}$.

Quadro 2 - Frequência de comportamento dos leitões em diferentes turnos avaliados entre os dias 06/02/2018 e 22/02/18

\begin{tabular}{|l|c|c|c|c|}
\hline Comportamento & $\begin{array}{c}\text { Manhã } \\
(\%) \\
5 \mathrm{~h} \text { às } \\
7 \mathrm{~h}\end{array}$ & $\begin{array}{c}\text { Tarde } \\
(\%) \\
12 \mathrm{~h} \text { às } \\
14 \mathrm{~h}\end{array}$ & Média & $\begin{array}{c}\text { Valor } \\
\text { de P }\end{array}$ \\
\hline $\begin{array}{l}\text { Mordendo, brigando } \\
\text { ou arranhando }\end{array}$ & 0,50 & 0,57 & 0,54 & 0,7880 \\
\hline Fuçando a baia & 6,39 & 5,54 & 5,96 & 0,8595 \\
\hline Fuçando o outro & 7,04 & 5,93 & 6,48 & 0,9296 \\
\hline Dormindo ou deitado & 68,96 & 70,44 & 69,70 & 1,0000 \\
\hline Comendo ou bebendo & 13,28 & 12,91 & 13,09 & 0,5650 \\
\hline Locomovendo-se & 1,81 & 2,17 & 1,99 & 0,7900 \\
\hline Parado ou excretando & 1,09 & 1,15 & 1,12 & 0,9636 \\
\hline Brincando entre si & 0,93 & 1,30 & 1,11 & 0,4202 \\
\hline Total & 100,00 & 100,00 & 100,00 & \\
\hline
\end{tabular}

Médias não diferiram pelo teste de Man-Whitney ( $\mathrm{p}>0,05)$.

Fonte: dados da pesquisa.

Quadro 3 - Médias de temperatura ambiente $\left({ }^{\circ} \mathrm{C}\right)$ e umidade relativa do ar (\%), registrados entre os dias 06/02/2018 e $22 / 02 / 2018$

\begin{tabular}{|l|c|c|}
\hline & Manhã & Tarde \\
\hline Temperatura $\left({ }^{\circ} \mathrm{C}\right)$ & $24,9 \pm 1,0$ & $28,2 \pm 1,7$ \\
\hline Umidade (\%) & $84,1 \pm 3,7$ & $72,6 \pm 7,1$ \\
\hline
\end{tabular}

Fonte: dados da pesquisa.

As médias de temperatura observadas às 05 horas da manhã e a média da umidade registrada às 12 horas no experimento são consideradas de conforto térmico para leitões de creche, e vão ao encontro com a temperatura e umidade considerada ideal para Ferreira (2011) e Sousa Júnior (2011), porém a média de temperatura de $28{ }^{\circ} \mathrm{C}$ registrada às 12 horas e a média de umidade de $84 \%$, registrada às 05 horas da manhã, não apresentaram efeito no comportamento dos leitões observados nos dois períodos.

Conforme apresentado, os leitões mostraram comportamentos semelhantes em ambos os horários de observação, predominando o comportamento dormindo ou deitado. Segundo Kiefer et al. (2009), leitões mantidos sob ambiente de conforto térmico apresentam este tipo de comportamento com frequência. Os resultados deste trabalho corroboram com os resultados encontrados por Campos et al. (2010) para o comportamento deitado, que não apresentou diferenças significativas e os animais foram expostos a médias de temperaturas similares em ambos os trabalhos, em que se observaram que leitões criados em creches suspensas passavam a maior parte do tempo deitados mesmo sob temperaturas mais elevadas, o que pode ser em virtude da baixa condutividade térmica do piso plástico, material que era utilizado nas baias deste experimento, propiciando assim maior conforto térmico para os leitões. Segundo Andersen (2008), os animais exibem conforto térmico quando deitados um ao lado do outro e, assim, foi observado nas filmagens durante a manhã e à tarde, em que quase não houve diferença nas médias de temperatura, e ficou dentro da faixa de conforto térmico.

Segundo Santos et al. (2018), produzir suínos em região semiárida, sob altas temperaturas, exige mais cuidados com relação ao material utilizado na construção dos galpões, como também o cuidado com o uso adequado de sistema de ventilação (natural e artificial). No caso do galpão do presente estudo, não havia ventilador, porém a ventilação natural era boa, não deixando os animais ficarem expostos ao calor extremo para não entrarem em estresse térmico, além do controle das cortinas que era bem feito.

Em um estudo realizado por Araújo et al. (2011) foram verificadas alterações comportamentais ao se comparar leitões desmamados com diferentes idades, os animais desmamados aos 21 dias apresentaram maior comportamento de estresse nas 63 horas que sucedem o desmame do que animais desmamados com 35 dias. Neste estudo, os animais foram desmamados aos 21 dias, entretanto as observações se iniciaram após 19 dias de creche, quando os leitões já estavam adaptados ao novo ambiente e ao novo grupo expressando poucos comportamentos estereotipados (fuçando o outro).

No comportamento de fuçar o outro, verifica-se o belly nosing, que é o ato de massagear a barriga de outro leitão, sendo observado em leitões que são desmamados muito cedo. Weary et al. (1999) ressaltam que leitões desmamados com duas semanas desenvolvem mais esse comportamento que animais desmamados com quatro semanas. Oostindjer et al. (2014) observaram diferenças significativas para o comportamento de belly nosing em leitões submetidos ao enriquecimento ambiental, quando comparado aos leitões alojados em ambiente sem enriquecimento ambiental. 
Nos dois momentos do dia avaliados foi verificado que muitos animais ficaram deitados, reflexo de um ambiente monótono, o que pode causar comportamentos anormais, como foi relatado por Carvalho et al. (2013), esse comportamento anormal pode não ser só representado por ficar muito tempo deitado, mas também pressionar o bebedouro e não beber água, vocalizar ou ficar parado (FRASER; BROOM, 1990).

Este trabalho teve resultados semelhantes aos resultados encontrados no trabalho de Bezerra et al. (2019), em que os animais passaram mais tempo expressando os comportamentos dormindo ou deitado e comendo ou bebendo. De acordo com este estudo, os leitões passaram a maior parte do tempo deitados ou dormindo, comportamento evidenciado em vários estudos como o mais frequente na ausência de enriquecimento ambiental na fase de creche (OLLIVEIRA et al., 2016; ANDRADE et al., 2019). Segundo Andrade et al. (2019), leitões na fase de creche confinados sem enriquecimento ambiental apresentaram frequências maiores para as características deitado, andando e vocalizando, quando comparado ao grupo com enriquecimento ambiental. Enquanto Campos et al. (2010) observaram que na ausência de enriquecimento ambiental, os leitões brincam menos, fuçam mais e apresentam aumento de comportamento estereotipado. Quando se enriquece o ambiente se quebra a monotonia estimulando o leitão a apresentar outros comportamentos como brincar e explorar o ambiente em detrimento das atividades de brigar, vício de sucção e manipulação da cauda (BEZERRA et al., 2019).

\section{Conclusão}

Manter os animais na temperatura e umidade ideais na fase de creche é de extrema importância para que os leitões consigam expressar seu potencial produtivo, além da avaliação diária desses parâmetros é de grande importância observar o comportamento dos animais, pois esse vai indicar se os animais estão de fato em conforto térmico.

\section{Referências}

ANDERSEN, H.M.L. et al. The ear skin temperature as an indicator of the thermal comfort of pigs. Appl. Anim. Behaviour Scie., v.113, p. 43-56, 2008. doi: 10.1016/j.applanim.2007.11.003.

ANDRADE, T.V. et al. Comportamento de leitões na fase de creche submetidos ao enriquecimento ambiental. Rev. Ciên. Agrovet., v.18. n.3. p.346-351, 2019. doi: 10.5965/223811711832019346.

ARAÚJO, W.G. et al. Comportamento de leitões em função da idade de desmame. Rev. Bras. Saúde Prod. Anim., v.12, n.3, p.758-769, 2011.

ASSOCIAÇÃO BRASILEIRA DE PROTEÍNA ANIMAL ABPA. Relatório Anual 2016. 2016.
BEZERRA, B.M.O. et al. Avaliação do estresse e do desempenho de suínos na fase de creche, empregando-se técnicas de enriquecimento ambiental. Arq. Bras. Med. Vet. Zoot., v.71, n.1, p.281-290, 2019. doi: 10.1590/1678-4162-10209.

CAMPOS, J.A. et al. Enriquecimento ambiental para leitões na fase de creche advindos de desmame aos 21 e 28 dias. Rev. Bras. Ciên. Agrár., v.5, p.272-278, 2010. doi: 10.5039/agraria. v5i2a660.

CARVALHO, C.M.C. et al. Bem Estar na suinocultura. Nutrit., v.11, n.2, p.2272-2286, 2013.

DAMASCENO, F.A. et al. avaliação do conforto térmico e comportamento de leitões influenciado por diferentes sistemas de aquecimento. Energ. Agric., v.34, n.3, p.364-376, 2019. doi:10.17224/EnergAgric.2019v34n3p364-376.

FERREIRA, R.A. Maior produção com melhor ambiente: para aves, suínos e bovinos. Viçosa: Aprenda Fácil, 2011.

FOPPA, L. et al. Pig's behavioral response in nursery and growth phases to environmental enrichment objects. Span. J. Agric. Res., v.16, n.3, p.10-16. 2018. doi: 10.5424/sjar/2018163-12303.

FRASER, A.F.; BROOM, D.M. Farm animal behaviour and welfare. Bailli’ere Tindall: London, 1990.

KIEFER, C. et al. Resposta de suínos em crescimento mantidos em diferentes temperaturas. Rev. Arch. Zoot., v.58, n.221, p.5564, 2009.

KUMMER, R. et al. Fatores que influenciam no desempenho dos leitões na fase de creche. Acta Scie. Vet., v.37, Supl 1, p.195-209, 2009.

OLIVEIRA, R.F. et al. Environmental enrichment improves the performance and behavior of piglets in the nursery phase. Arq. Bras. Med. Vet. Zoot., v.68, n.2, p.415-421, 2016. doi: 10.1590/1678-4162-8253.

OOSTINDJER, M. et al. Facilitating 'learning from mom how to eat like a pig' to improve welfare of piglets around weaning. Appl. Anim. Behav. Sci., v.160, p.19-30, 2014. doi: 10.1016/j. applanim.2014.09.006.

QUINIOU, N.; NOBLET, J. Influence of high ambient temperatureon performance of multiparous lactating sows. J. Anim. Sci., v.77, n.8, p.2124-2134, 1999. doi: 10.2527/1999.7782124x.

SANTOS, T.C. et al. Influência do ambiente térmico no comportamento e desempenho zootécnico de suínos. Rev. Ciên. Agrovet., v.17, n.2, p.241-253, 2018. doi: $10.5965 / 223811711722018241$.

SNOWDON, C.T. O significado da Pesquisa em Comportamento Animal. Est. Psicol.; São Paulo, v.4, p.365-373, 1999. doi: 10.1590/S1413-294X1999000200011.

SOUSA JÚNIOR, V.R. et al. Iluminação artificial no desempenho de leitões na fase de creche. Acta Scie. Anim. Scie., v.33, n.4, p.403-408, 2011. doi: 10.4025/actascianimsci.v33i4.10828.

SPOOLDER, H.A.M.; EDWARDS, A.S.; CORNING, S. Effects of group size and feeder space allowance on welfare in finishing pigs. J. Anim. Scie., v.69, p.481-489, 1999. doi: 10.1017/ S135772980005133X.

WEARY, D.; APPLEBY, M.; FRASER, D. Responses of piglets to early separation from the sow. Appl. Anim. Behav. Scie., v.63, 